\title{
Variation in Provider Identification of Obesity by Individual- and Neighborhood-Level Characteristics among an Insured Population
}

\author{
Sara N. Bleich, ${ }^{1}$ Jeanne M. Clark, ${ }^{2,3,4}$ Suzanne M. Goodwin, ${ }^{1}$ Mary Margaret Huizinga, ${ }^{2,3}$ \\ and Jonathan P. Weiner ${ }^{1}$ \\ ${ }^{1}$ Department of Health Policy and Management, Johns Hopkins Bloomberg School of Public Health, 624 N. Broadway, \\ Room 451, Baltimore, MD 21205, USA \\ ${ }^{2}$ Division of General Internal Medicine, Department of Medicine, Johns Hopkins University School of Medicine, \\ Baltimore, MD 21205, USA \\ ${ }^{3}$ Welch Center for Prevention, Epidemiology, and Clinical Research, Johns Hopkins Medical Institutions, \\ Baltimore, MD 21205, USA \\ ${ }^{4}$ Department of Epidemiology, Johns Hopkins Bloomberg School of Public Health, Baltimore, MD 21205, USA
}

Correspondence should be addressed to Sara N. Bleich, sbleich@jhsph.edu

Received 25 August 2009; Revised 4 January 2010; Accepted 23 February 2010

Academic Editor: Mark A. Pereira

Copyright (C) 2010 Sara N. Bleich et al. This is an open access article distributed under the Creative Commons Attribution License, which permits unrestricted use, distribution, and reproduction in any medium, provided the original work is properly cited.

\begin{abstract}
Objective. The purpose of this study was to examine whether neighborhood- and individual-level characteristics affect providers' likelihood of providing an obesity diagnosis code in their obese patients' claims. Methods. Logistic regressions were performed with obesity diagnosis code serving as the outcome variable and neighborhood characteristics and member characteristics serving as the independent variables ( $N=16,151$ obese plan members). Results. Only 7.7 percent of obese plan members had an obesity diagnosis code listed in their claims. Members living in neighborhoods with the largest proportions of Blacks were 29 percent less likely to receive an obesity diagnosis $(P<.05)$. The odds of having an obesity diagnosis code were greater among members who were female, aged 44 or below, hypertensive, dyslipidemic, BMI $\geq 35 \mathrm{~kg} / \mathrm{m}^{2}$, had a larger number of provider visits, or who lived in an urban area (all $P<.05)$. Conclusions. Most health care providers do not include an obesity diagnosis code in their obese patients' claims. Rates of obesity identification were strongly related to individual characteristics and somewhat associated with neighborhood characteristics.
\end{abstract}

\section{Introduction}

Although obesity disproportionately affects minorities and the socioeconomically disadvantaged [1], prior research has shown that clinician diagnosis and treatment of obesity is not consistent with underlying population prevalence [2-5]. Health care providers are more likely to diagnose younger adults and women as obese [6] and more likely to encourage weight loss activities among individuals who are White [7], are middle aged [8-10], or who have a higher socioeconomic status (SES) $[8,11,12]$.

The relationship between residence in a socioeconomically deprived neighborhood and obesity diagnosis has not been studied. Research in other disease areas has identified a relationship between neighborhood characteristics and disease diagnosis. For example, residence in low SES neighborhoods has been associated with an increased likelihood of late-stage cancer diagnosis, particularly among Black and Hispanic women [2].

Social ecological theory forms the theoretical basis for this study and conceptualizes individuals as nested within broad social/environmental networks that influence their perceptions, outlooks, and behaviors. It suggests that neighborhood racial characteristics and SES may be important influences to consider in addition to individual-level characteristics $[13,14]$. According to social ecological theory, individuals' decisions and actions depend not only on their characteristics but also on the social forces that shape the 
contexts in which they live. In the case of physicians, these forces could originate from social institutions (e.g., health care systems, medical school), media, peer groups, or cultural norms. Each of these factors may serve as an intervening or moderating factor in the relationship between neighborhood characteristics and provider diagnosis of obesity.

Neighborhood characteristics may influence providers' diagnosis of obesity through several possible pathways. For example, the location of residence may serve as a proxy for the availability of health system resources (e.g., health professional supply, health systems infrastructure, nutrition/fitness services). In areas where healthcare resources are limited, the diagnosis of obesity may be prioritized lower than acute medical problems resulting from excess body weight such as hypertension, type 2 diabetes, or hyperlipidemia. Social norms about body weight in a given neighborhood of residence may influence providers' diagnosis of obesity. For example, Blacks, who are more accepting of excess weight, have less body weight dissatisfaction, and have higher body weight ideals compared to Whites $[15,16]$, may be less likely to cite body weight as a chief complaint. As a result, health care providers working in areas serving predominantly Black members may be less likely to diagnose their patients as obese. Underlying population prevalence of obesity in a given neighborhood may negatively or positively impact physician diagnosis of obesity. On the one hand, increased exposure to obese patients, particularly in areas with smaller healthcare facilities servicing a more homogenous population, may increase the likelihood of a physician diagnosis. On the other hand, negative physician attitudes towards patient body weight [17] and recent research which suggests that higher patient body mass index is associated with lower physician respect [18] may reduce the likelihood of an obesity diagnosis claim in areas characterized by a higher population prevalence.

Provider diagnosis of obesity can have significant clinical and behavioral consequences. Provider recognition of obesity is one of the biggest predictors of patient receipt of weight-related counseling and is associated with receipt of obesity-related services and patient self-efficacy $[19,20]$. Also, patients who are told by their physicians that they are overweight are more likely to lose weight compared to those who are not told [21, 22]. Moreover, patients who are counseled about their weight or weight-related behaviors are more likely to report working on those areas $[8,10,23]$, and patients who are advised by their physician to modify their behavior are generally more confident and motivated to engage in lifestyle modifications (e.g., dietary changes, increased physical activity) $[8,20,24]$.

The purpose of this paper was to identify variation in provider identification of obesity in claims data by both neighborhood- and individual-level characteristics among obese, insured individuals. We hypothesized that plan members living in lower SES neighborhoods or neighborhoods with higher percentages of minority residents would be less likely to be diagnosed with obesity by their providers. We further hypothesized that obese plan members who are female, younger, and who had higher body mass indices
(BMIs) would be more likely to receive an obesity diagnosis code in their claims.

A key contribution of this study to the existing literature is its inclusion of neighborhood characteristics in the analyses, which have received little attention to date. In light of current federal priorities to reduce obesity and eliminate health disparities [25-27], there is a pressing need to better understand how neighborhood characteristics contribute to providers' diagnosis of obesity.

\section{Methods}

2.1. Data. To examine whether neighborhood- and member-level characteristics affect whether providers include an obesity diagnosis code in their obese patients' claims, we used 2002-2005 claims data linked to health risk assessment (HRA) data for a sample of health plan members enrolled in one of three Blue Cross Blue Shield (BCBS) plans from different sections of the country. The claims data included inpatient, outpatient, professional, and pharmacy claims records. The HRAs were administered through an in-person clinical encounter, an online survey tool on the BCBS plan's website or direct mailing to eligible plan members (two health plan sites). For plan members completing an online or paper-based survey (two health plan sites), height and body weight were self-reported; members who completed an HRA during an in-person clinical encounter (one health plan site) had their height and body weight measured directly by a health care provider. Neighborhood data were obtained from the 2000 U.S. Census and linked to the members' claims and HRA data based on their ZIP code listed in the enrollment file.

BCBS members were excluded from the study sample if they were enrolled less than 6 months in the year in which they completed an HRA, were less than 18 years old or their age was missing, had a pregnancy and/or delivery claim during 2002-2005, had a body mass index (BMI) less than $30 \mathrm{~kg} / \mathrm{m}^{2}$ or greater than $100 \mathrm{~kg} / \mathrm{m}^{2}$, or were missing height or body weight data needed to calculate their BMI. Some members eligible for the study were found to have multiple HRA records; in such cases, the most recent record was selected. The final study sample consisted of 16,151 obese adult plan members. During the study period, all three BCBS plans covered weight loss medications, nutritional counseling, and bariatric surgery as part of their benefits.

The data used in this study met Health Insurance Portability and Accountability Act's (HIPAA) definition of a limited data set. The data were secured and used in accordance with federal standards for protecting the confidentiality of the personal health information of the enrollee. The Johns Hopkins University Office of Research Subjects deemed the study to be exempt from federal regulations because the research activities were considered to be of minimal risk to subjects.

\subsection{Measures}

2.2.1. Outcome Variable. The outcome variable of interest was an obesity claim, specifically, whether the provider 
included an obesity diagnosis code in their obese patients' claims. An obesity claim was indicated by International Classification of Diseases, Ninth Revision, Clinical Modification (ICD-9-CM) codes in the claims data. In particular, an obesity claim was defined by the presence of ICD-9 codes for obesity (ICD-9 codes: 278, 278.0, 278.00, 278.01, 278.1, V77.8, or V85.3-V85.4).

2.2.2. Independent Variables. The main independent neighborhood-level variables of interest (measured at the ZIP code level) were the proportion of Black residents, median household income adjusted for inflation, percentage of residents with a high school diploma, and percentage of residents living in an urban area (each measured in tertiles) as well as the percentage of people living above the federal poverty line (based on a poverty income ratio at or above 1.00). The following member-level variables also were included in the models for their moderating or confounding influence on the outcome variable: age, sex, mean BMI obesity class (class I: BMI $30.0-34.9 \mathrm{~kg} / \mathrm{m}^{2}$, class II: BMI $35.0-39.9 \mathrm{~kg} / \mathrm{m}^{2}$, and class III: BMI $\geq 40 \mathrm{~kg} / \mathrm{m}^{2}$ ), and diagnosis of type 2 diabetes, hypertension, or dyslipidemia. The comorbidities were measured as binary outcomes based on the presence of relevant ICD-9-CM codes in the claims data (see Tables 3 and 4 for codes). We also controlled for the distinct number of providers and the number of specialists seen by the members in the year in which the HRA data were collected.

2.3. Statistical Analysis. We used a multilevel logistic regression model to measure the associations between the outcome variable-obesity claim — and the neighborhood member characteristics. Analyses were performed using the Stata, version 9.2, software package (StataCorp LP, College Station, TX).

\section{Results}

3.1. Characteristics of the Study Sample. Table 1 reports the characteristics of the study sample overall and by the presence or absence of an obesity diagnosis code in their claims data. With respect to neighborhood characteristics (measured at the ZIP code-level), the mean proportion of Black residents was $5.3 \%$, the median household income was $\$ 46,759$, the mean percentage of high school graduates was $70.5 \%$, the mean proportion of members living in urban ZIP codes was $81.7 \%$, and the mean proportion of residents above the federal poverty threshold was $87.6 \%$. These estimates for the study sample were relatively similar to 2000 U.S. Census estimates of $12.3 \%$ black, $\$ 41,994$ median household income, $80.4 \%$ high school graduates, $79.0 \%$ urban, and $88.7 \%$ above the federal poverty threshold [28].

With respect to member-level characteristics, $48.0 \%$ of the sample was female, the mean age was 48 years, $29.2 \%$ were hypertensive, $10.3 \%$ had type 2 diabetes, $26.8 \%$ had dyslipidemia, the mean BMI was $34.7 \mathrm{~kg} / \mathrm{m}^{2}$, and $64.9 \%$ were class I obese. The mean number of distinct providers seen in the year they completed the HRA was 2.0 and the mean number of specialists seen in that same year was 8.2. Nearly

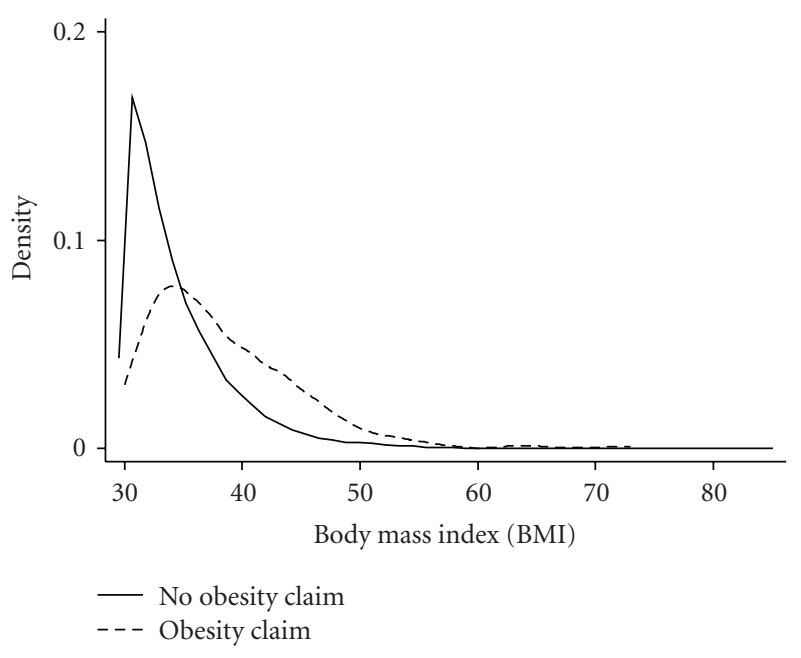

FIGURE 1: BMI in obese study sample for persons with and without an obesity claim. Note that obesity was defined as a body mass index, BMI $\geq 30 \mathrm{~kg} / \mathrm{m}^{2}$.

$8 \%$ of the sample had an obesity diagnosis code recorded in their claims records.

3.2. Obesity Claim by BMI. Figure 1 illustrates the distribution of BMI by obesity claim. The mean BMI of obese members with an obesity claim was significantly higher than the mean BMI for members without an obesity claim $\left(38.4 \mathrm{~kg} / \mathrm{m}^{2}\right.$ versus $\left.34.5 \mathrm{~kg} / \mathrm{m}^{2}, P<.01\right)$.

3.3. Neighborhood- and Individual-Level Predictors of Obesity Claim. Table 2 shows the multilevel logistic regression results relating neighborhood- and member-level characteristics to whether the provider included an obesity diagnosis code in the patients' claims. Tertile ranges for the neighborhood-level variables in the model can be found in Table 4. After controlling for individual-level characteristics, BCBS members living in neighborhoods with the largest proportion of Blacks were 29 percent less likely to receive an obesity claim $(\mathrm{OR}=0.71 ; 95 \% \mathrm{CI}$ : $0.57,0.89)$. BCBS members living in neighborhoods with the second largest proportion of Black residents were 21 percent less likely to receive an obesity claim (OR $=0.79$; 95\% CI: 0.64, 0.96). We also observed a significant association between provider identification of obesity in patient claims data and urbanity; BCBS members living in neighborhoods with the second largest proportion of urban residents were 62 percent more likely to receive an obesity claim $(\mathrm{OR}=1.62 ; 95 \% \mathrm{CI}$ : $0.31,2.01$ ). While we did not observe associations between household income and obesity diagnosis code in the patients' claims, the direction of the effect was consistent with our study hypothesis that plan members living in lower SES neighborhoods would be less likely to be diagnosed with obesity by their providers. At the individual-level, the odds of having an obesity claim were greater among plan members who were female ( $\mathrm{OR}=1.47 ; 95 \% \mathrm{CI}: 1.27,1.96)$, age 44 or below $(\mathrm{OR}=1.70 ; 95 \%$ CI: $1.48,1.96)$, with hypertension 
TABLE 1: Characteristics of the study sample $(N=16,151)$.

\begin{tabular}{|c|c|c|c|}
\hline & \multirow{2}{*}{ Overall } & \multicolumn{2}{|c|}{ Obesity claim } \\
\hline & & Yes & No \\
\hline \multicolumn{4}{|l|}{ Neighborhood-level characteristics (ZIP code level) } \\
\hline Mean proportion of Black residents & $5.3 \%$ & $4.0 \%$ & $5.3 \%$ \\
\hline Median household income & $\$ 43,846$ & $\$ 44,908$ & $\$ 43,636$ \\
\hline Mean percent high school graduate & $70.5 \%$ & $70.6 \%$ & $70.5 \%$ \\
\hline Mean proportion urban & $81.7 \%$ & $84.3 \%$ & $81.5 \%$ \\
\hline Mean proportion of residents above federal poverty & $87.6 \%$ & $87.2 \%$ & $87.6 \%$ \\
\hline \multicolumn{4}{|l|}{ Member-level characteristics } \\
\hline Female & $52.0 \%$ & $66.1 \%$ & $50.9 \%$ \\
\hline Mean age & 48.4 years & 47.2 years & 48.5 years \\
\hline Hypertension & $29.2 \%$ & $46.4 \%$ & $27.8 \%$ \\
\hline Type 2 Diabetes & $10.3 \%$ & $15.9 \%$ & $9.8 \%$ \\
\hline Dyslipidemia & $26.8 \%$ & $41.7 \%$ & $25.5 \%$ \\
\hline Mean BMI & 34.7 & 37.6 & 34.5 \\
\hline \multicolumn{4}{|l|}{ Obesity class } \\
\hline Class I & $64.9 \%$ & $42.2 \%$ & $66.8 \%$ \\
\hline Class II & $23.1 \%$ & $29.8 \%$ & $22.6 \%$ \\
\hline Class III & $12.0 \%$ & $28.1 \%$ & $10.6 \%$ \\
\hline Mean number of distinct provider seen in HRA year & 2.0 & 2.9 & 1.9 \\
\hline Mean number of specialist visits in HRA year & 8.2 & 12.0 & 7.8 \\
\hline \multicolumn{4}{|l|}{ Obesity claim } \\
\hline Physician identification of obesity in claims data & $7.7 \%$ & - & - \\
\hline
\end{tabular}

$(\mathrm{OR}=1.56 ; 95 \% \mathrm{CI}: 1.29,1.87)$, with dyslipidemia $(\mathrm{OR}=$ 1.56; $95 \%$ CI: $1.30,1.88$ ), with class II or III obesity (class II: OR $=2.02$; $95 \%$ CI: 1.71 , 2.38; class III: OR $=4.02$; 95\% CI: $3.38,4.75)$ or who had a greater number of distinct provider visits $(\mathrm{OR}=1.20 ; 95 \% \mathrm{CI}: 1.16,1.23)$.

\section{Discussion}

The central aim of this study was to identify variation in provider identification of obesity (as indicated by claims data) by neighborhood- and member-level characteristics among an insured population of obese Blue Cross Blue Shield plan members. Overall, we found that the proportion of Black residents in the members' neighborhood was moderately associated with whether a provider included an obesity diagnosis code in their obese patients' claims and that individual-level characteristics (female gender, younger age, obesity-related comorbidities, and BMI $\geq 35 \mathrm{~kg} / \mathrm{m}^{2}$ ) were strongly associated with provider identification of obesity. Our results also suggest that most providers do not record obesity as a reason for clinical visits when billing private insurers. While all BCBS plans included in this study covered weight loss medications, nutritional counseling, and bariatric surgery during the study period, the widespread perception among providers that obesity is not a reimbursable medical condition [29-31] may have contributed to this low diagnosis reporting rate.

These findings are similar to those of previous research. Like earlier studies, we observed differences in rates of obesity diagnosis codes by patients' demographic characteristics
$[6,32,33]$. Also similar to prior research, we observed higher rates of obesity claims among members with obesity-related comorbidities [6] and higher BMIs [34]. Also like previous studies $[35,36]$, we observed low rates of obesity diagnosis codes.

This study makes four important contributions to the evidence base. To our knowledge, this is the first paper to examine associations between neighborhood characteristics and receipt of an obesity claim. Second, because our study population is insured, our analyses are not confounded by financial barriers to access. Third, BCBS is the largest health insurer which likely makes the plans included in this study typical of the ones used by a large proportion of the U.S., thereby increasing the generalizability of study results. Fourth, the BCBS data used in this analysis are the largest and most current database that has been used to examine provider practice pattern of adult obesity care.

4.1. Limitations. There are several limitations to this analysis that deserve discussion. First, the cross-sectional nature of the study design prevents conclusions about causation. Second, the measure of obesity was based primarily on self-reported height and body weight. Because women tend to underestimate their true body weight and men tend to overestimate their actual height [37], some members may have been included or excluded from the sample erroneously and/or their BMI may have been misclassified. Likewise, individuals' obesity classification may have changed over time depending on the timing of the HRA administration and medical encounters. Such changes also may have 
TABLE 2: Adjusted association of neighborhood characteristics and obesity claim among insured population $(N=13,434)$.

\begin{tabular}{|c|c|}
\hline & OR $(95 \% \mathrm{CI})$ \\
\hline \multicolumn{2}{|l|}{ Neighborhood-level characteristics } \\
\hline \multicolumn{2}{|l|}{ Proportion of Black residents } \\
\hline Tertile 3 (highest) & $0.71^{\dagger}(0.57,0.89)$ \\
\hline Tertile 2 & $0.79^{\dagger}(0.64,0.96)$ \\
\hline Tertile 1 (lowest) & 1.00 (reference) \\
\hline \multicolumn{2}{|l|}{ Median household income } \\
\hline Tertile 3 (highest) & $1.01(0.84,1.38)$ \\
\hline Tertile 2 & $0.98(0.78,1.24)$ \\
\hline Tertile 1 (lowest) & 1.00 (reference) \\
\hline \multicolumn{2}{|l|}{ Percent high school graduate } \\
\hline Tertile 3 (highest) & $0.91(0.72,1.15)$ \\
\hline Tertile 2 & $1.14(0.91,1.42)$ \\
\hline Tertile 1 (lowest) & 1.00 (reference) \\
\hline \multicolumn{2}{|l|}{ Percent urban } \\
\hline Tertile 3 (highest) & $1.10(0.88,1.38)$ \\
\hline Tertile 2 & $1.62^{\dagger}(1.31,2.01)$ \\
\hline Tertile 1 (lowest) & 1.00 (reference) \\
\hline $\begin{array}{l}\text { Percent above federal poverty } \\
\text { threshold }\end{array}$ & $0.99(0.97,1.00)$ \\
\hline \multicolumn{2}{|l|}{ Member-level characteristics } \\
\hline Female & $1.47^{\dagger}(1.27,1.70)$ \\
\hline \multicolumn{2}{|l|}{ Age } \\
\hline Age 44 and below & $1.67^{\dagger}(1.45,1.92)$ \\
\hline Age 45 and above & 1.00 (reference) \\
\hline Hypertension & $1.50^{\dagger}(1.26,1.80)$ \\
\hline Type 2 Diabetes & $0.95(0.80,1.13)$ \\
\hline Dyslipidemia & $1.54^{\dagger}(1.28,1.86)$ \\
\hline \multicolumn{2}{|l|}{ Obesity class } \\
\hline Class III & $4.12^{\dagger}(3.45,4.89)$ \\
\hline Class II & $2.04^{\dagger}(1.72,2.41)$ \\
\hline Class I & 1.00 (reference) \\
\hline $\begin{array}{l}\text { Number of distinct providers } \\
\text { seen in HRA year }\end{array}$ & $1.17^{\dagger}(1.13,1.21)$ \\
\hline $\begin{array}{l}\text { Number of specialist visits in } \\
\text { HRA year }\end{array}$ & $1.01(0.99,1.01)$ \\
\hline
\end{tabular}

${ }^{\dagger}$ Statistically significant at $P<.05$.

Note that the sample size in this model is smaller than the study sample due to missing individual-level characteristics among plan members.

affected sample selection and BMI classification. Third, some providers may have verbally indicated that their patients were obese, or recorded obesity in the medical records, but did not submit the diagnoses in the insurance claims. We are unable to determine the extent to which patients were diagnosed with obesity but their diagnoses were not recorded in the insurance claims. Fourth, factors other than those included in the models (e.g., member race; provider race, age, gender, location of training; type of hospital) may influence providers' diagnosis of obesity. Unfortunately, data for measuring those variables were not available. If
TABle 3: ICD-9 Diagnostic Codes.

\begin{tabular}{ll}
\hline Diagnosis & ICD-9 Code \\
\hline Obesity & $278,278.0,278.00,278.01,278.1$, V77.8, or \\
Hypertension & V85.3-V85.4 \\
& $201-405$ \\
& $250,250.0,250.00,250.02,250.1,250.10$, \\
Type 2 Diabetes & $250.32,250.2,250.20,250.22,250.3,250.30$, \\
& $250.52,250.6,250.60,250.62,250.7,250.70$, \\
& $250.72,250.8,250.80,250.82,250.9,250.90$, \\
Dyslipidemia & 250.92 \\
& $272.2-272.9$ \\
\hline
\end{tabular}

TABLE 4: Ranges of neighborhood-level variables.

\begin{tabular}{lc}
\hline & Range \\
\hline Proportion of Black residents & \\
Tertile 3 (highest) & $2.0 \%-95.8 \%$ \\
Tertile 2 & $0.6 \%-1.9 \%$ \\
Tertile 1 (lowest) & $0.0 \%-0.6 \%$ \\
Median household income & \\
Tertile 3 (highest) & $\$ 57,049-\$ 159,538$ \\
Tertile 2 & $\$ 39,543-\$ 56,951$ \\
Tertile 1 (lowest) & $\$ 0.0-\$ 39,526$ \\
Percent high school graduate & \\
Tertile 3 (highest) & $60.9 \%-100.0 \%$ \\
Tertile 2 & $55.9 \%-60.8 \%$ \\
Tertile 1 (lowest) & $19.8 \%-55.8 \%$ \\
Percent urban & \\
Tertile 3 (highest) & $99.8 \%-100.0 \%$ \\
Tertile 2 & $93.5 \%-99.7 \%$ \\
Tertile 1 (lowest) & $0.0 \%-93.4 \%$ \\
\hline
\end{tabular}

Note: The U.S. Census defines urban as densely settled areas containing at least 50,000 people (urban areas) and densely settled areas with a population of 2,500 to 49,999 (urban clusters).

these omitted variables affected the outcome, the results may be biased. Fifth, there may have been changes in sociodemographic characteristics between 2000, the year of the U.S. Census data used for measuring neighborhood characteristics, and 2002-2005, the years of the claims and HRA data used for measuring the outcome and member variables. If sociodemographic changes did occur, the study population may have been mischaracterized. However, it is unlikely that neighborhood characteristics changed significantly during the 3- to 5-year period and the study's use of tertiles minimizes the effect of any changes that did occur on the results. Sixth, for some study participants, the ZIP code of residence may not be the same as the location of care. Because the members' ZIP codes were obtained from the administrative data rather than the clinical data, providers may not be aware of the ZIP code where members live, which may explain why most of the neighborhood characteristics were not statistically significant. However, even in the absence of knowledge about members' zip code of enrollment, providers may have a general sense of the 
neighborhood characteristics of their members' place of residence. Seventh, three modes were used to collect the HRA data-an online survey tool on the BCBS plan's website, a direct mailing to eligible plan members, or an in-person clinical encounter. Differences in the mode of data collection may introduce some bias to the results. Finally, it is possible that plan members had an obesity diagnosis code reported in a claim earlier or later than the year in which they completed an HRA.

4.2. Future Research. The results of this study suggest the need for more research. Going forward, more research is needed to better understand the impact of neighborhood context on the likelihood that a physician provides an obesity diagnosis code in their obese patients' claims. In particular, why do individuals living in neighborhoods with the highest proportion of Black residents have a lower likelihood of having an obesity claim? And why do individuals living in more urbanized areas have a higher likelihood of having an obesity claim? Are there other, potentially more precise, neighborhood characteristics (not included in this analysis) that affect provider obesity claims? What is the appropriate unit of analysis to examine the relationship between neighborhood context and provider identification of obesity (e.g., ZIP code, Census block)? A better understanding of the association between neighborhood context and provider obesity claims could help better target local, state, and national efforts aimed at reducing obesity rates and eliminating health disparities [27].

\subsection{Clinical, Public Health, and Research Implications. Given} that receipt of an obesity diagnosis is an important gateway to receipt of obesity care $[8,10,20-24]$ and given the considerable costs associated with obesity and its comorbidities [38], insurers may consider increasing their coverage of obesity management and treatment as a way of reducing obesity-related costs in the long run. Such a change in member benefits would need to be clearly communicated since many physicians identify lack of payment by insurance companies as a key barrier to providing obesity care [29-31].

Physicians and other health care professionals are uniquely positioned to have an impact on the obesity epidemic in the U.S. The results of this study suggest, however, that they may be missing opportunities to educate and treat their obese patients. Given the considerable health and economic consequences of obesity and its related comorbidities [39], providers who consistently diagnose their obese patients may facilitate modest weight loss at the individual-level which, in turn, may encourage significant health benefits and reduced costs at the population-level $[40,41]$. Finally, the low level of obesity diagnoses reported in claims suggests that claims data may be a poor source of data for understanding trends in obesity diagnosis and treatment.

\section{Conclusion}

We found very low rates of obesity claims among an insured, obese population, particularly for members who were morbidly obese or living in neighborhoods with a higher proportion of Black residents. These findings indicate the need for better systems or incentive structures to encourage more appropriate diagnosis of obese patients in claims data.

\section{Author Contributions}

Sara N. Bleich and Jonathan P. Weiner conceived the study and developed the hypotheses. Sara N. Bleich analyzed the data. All authors contributed to the interpretation of study findings. Sara N. Bleich drafted the manuscript and all authors contributed to the final draft. Sara N. Bleich is the guarantor.

\section{Acknowledgments}

This study was funded by unrestricted research grants from Ethicon Endo-Surgery, Inc. (a Johnson \& Johnson company); Pfizer, Inc; and GlaxoSmithKline. The data and in-kind database development support and guidance were provided by the BCBS Association, BCBS of Tennessee, BCBS of Hawaii, BCBS of Michigan, BCBS of North Carolina, Highmark, Inc. (of Pennsylvania), Independence Blue Cross (of Pennsylvania), Wellmark BCBS of Iowa, and Wellmark BCBS of South Dakota. Technical assistance with the claims data was provided by Thomas Richards, Andrew Shore, and Hsien-Yen Chang of Johns Hopkins Bloomberg School of Public Health.

\section{References}

[1] C. L. Ogden, M. D. Carroll, L. R. Curtin, M. A. McDowell, C. J. Tabak, and K. M. Flegal, "Prevalence of overweight and obesity in the United States, 1999-2004," Journal of the American Medical Association, vol. 295, no. 13, pp. 1549-1555, 2006.

[2] J. Barry and N. Breen, "The importance of place of residence in predicting late-stage diagnosis of breast or cervical cancer," Health and Place, vol. 11, no. 1, pp. 15-29, 2005.

[3] S. S. Merkin, L. Stevenson, and N. Powe, "Geographic socioeconomic status, race, and advanced-stage breast cancer in New York City," American Journal of Public Health, vol. 92, no. 1, pp. 64-70, 2002.

[4] P. B. Bach, L. D. Cramer, J. L. Warren, and C. B. Begg, "Racial differences in the treatment of early-stage lung cancer," The New England Journal of Medicine, vol. 341, no. 16, pp. 11981205, 1999.

[5] B. Smedley, A. Stith, and A. Nelson, Eds., Unequal Treatment: Confronting Racial and Ethnic Disparities in Health Care, National Academy Press, Washington DC, USA, 2002.

[6] R. S. Stafford, J. H. Farhat, B. Misra, and D. A. Schoenfeld, "National patterns of physician activities related to obesity management," Archives of Family Medicine, vol. 9, no. 7, pp. 631-638, 2000.

[7] J. Ma, G. G. Urizar Jr., T. Alehegn, and R. S. Stafford, "Diet and physical activity counseling during ambulatory care visits in the United States," Preventive Medicine, vol. 39, no. 4, pp. 815-822, 2004.

[8] D. A. Galuska, J. C. Will, M. K. Serdula, and E. S. Ford, "Are health care professionals advising obese patients to lose 
weight?" Journal of the American Medical Association, vol. 282, no. 16, pp. 1576-1578, 1999.

[9] K. M. McTigue, R. Harris, B. Hemphill, et al., "Screening and interventions for obesity in adults: summary of the evidence for the U.S. Preventive Services Task Force," Annals of Internal Medicine, vol. 139, no. 11, pp. 933-949, 2003.

[10] C. N. Sciamanna, D. F. Tate, W. Lang, and R. R. Wing, "Who reports receiving advice to lose weight? Results from a multistate survey," Archives of Internal Medicine, vol. 160, no. 15, pp. 2334-2339, 2000.

[11] D. A. Taira, D. G. Safran, T. B. Seto, W. H. Rogers, and A. R. Tarlov, "The relationship between patient income and physician discussion of health risk behaviors," Journal of the American Medical Association, vol. 278, no. 17, pp. 1412-1417, 1997.

[12] J. E. Jackson, M. P. Doescher, B. G. Saver, and L. G. Hart, "Trends in professional advice to lose weight among obese adults, 1994 to 2000," Journal of General Internal Medicine, vol. 20, no. 9, pp. 814-818, 2005.

[13] A. V. Diez-Roux, "Bringing context back into epidemiology: variables and fallacies in multilevel analysis," American Journal of Public Health, vol. 88, no. 2, pp. 216-222, 1998.

[14] K. R. McLeroy, D. Bibeau, A. Steckler, and K. Glanz, "An ecological perspective on health promotion programs," Health Education Quarterly, vol. 15, no. 4, pp. 351-377, 1988.

[15] S. Kumanyika, J. F. Wilson, and M. Guilford-Davenport, "Weight-related attitudes and behaviors of black women," Journal of the American Dietetic Association, vol. 93, no. 4, pp. 416-422, 1993.

[16] G. G. Bennett and K. Y. Wolin, "Satisfied or unaware? Racial differences in perceived weight status," International Journal of Behavioral Nutrition and Physical Activity, vol. 3, article 40, 2006.

[17] M. R. Hebl and J. Xu, "Weighing the care: physicians' reactions to the size of a patient," International Journal of Obesity, vol. 25, no. 8, pp. 1246-1252, 2001.

[18] M. M. Huizinga, L. A. Cooper, S. N. Bleich, J. M. Clark, and M. C. Beach, "Physician respect for patients with obesity," Journal of General Internal Medicine, vol. 24, no. 11, pp. 1236-1239, 2009.

[19] A. Bardia, S. G. Holtan, J. M. Slezak, and W. G. Thompson, "Diagnosis of obesity by primary care physicians and impact on obesity management," Mayo Clinic Proceedings, vol. 82, no. 8, pp. 927-932, 2007.

[20] M. W. Kreuter, S. G. Chheda, and F. C. Bull, "How does physician advice influence patient behavior? Evidence for a priming effect," Archives of Family Medicine, vol. 9, no. 5, pp. 426-433, 2000.

[21] B. T. Levy and P. S. Williamson, "Patient perceptions and weight loss of obese adults," Journal of Family Practice, vol. 27, no. 3, pp. 285-290, 1988.

[22] A. K. Kant and P. Miner, "Physician advice about being overweight: association with self-reported weight loss, dietary, and physical activity behaviors of US adolescents in the National Health and Nutrition Examination Survey, 19992002," Pediatrics, vol. 119, no. 1, pp. e142-e147, 2007.

[23] M. L. Loureiro and R. M. Nayga Jr., "Obesity, weight loss, and physician's advice," Social Science and Medicine, vol. 62, no. 10, pp. $2458-2468,2006$.

[24] J. Huang, H. Yu, E. Marin, S. Brock, D. Carden, and T. Davis, "Physicians' weight loss counseling in two public hospital primary care clinics," Academic Medicine, vol. 79, no. 2, pp. 156-161, 2004.
[25] S. B. Thomas, M. J. Fine, and S. A. Ibrahim, "Health disparities: the importance of culture and health communication," American Journal of Public Health, vol. 94, no. 12, p. 2050, 2004.

[26] National Center for Health Statistics, Healthy People 2000 Review, 1998-1999, Public Health Service, Hyattsville, Md, USA, 1999.

[27] US Department of Health and Human Services, Healthy People 2010: Understanding and Improving Health, U.S. Government Printing Office, Washington, DC, USA, 2000.

[28] US Census Bureau, Census 2000 Summary File 1 (SF 1), Matrix P1 and Summary File 3 (SF 3).

[29] R. F. Kushner, "Barriers to providing nutrition counseling by physicians: a survey of primary care practitioners," Preventive Medicine, vol. 24, no. 6, pp. 546-552, 1995.

[30] C. J. Billington, "The challenge of obesity management in primary care," The Journal of the American Board of Family Practice, vol. 13, no. 3, pp. 222-223, 2000.

[31] G. D. Foster, T. A. Wadden, A. P. Makris, et al., "Primary care physicians' attitudes about obesity and its treatment," Obesity Research, vol. 11, no. 10, pp. 1168-1177, 2003.

[32] E. M. Bertera, "Psychosocial factors and ethnic disparities in diabetes diagnosis and treatment among older adults," Health and Social Work, vol. 28, no. 1, pp. 33-42, 2003.

[33] K. Nelson, K. Norris, and C. M. Mangione, "Disparities in the diagnosis and pharmacologic treatment of high serum cholesterol by race and ethnicity: data from the Third National Health and Nutrition Examination Survey," Archives of Internal Medicine, vol. 162, no. 8, pp. 929-935, 2002.

[34] C. B. Ruser, L. Sanders, G. R. Brescia, et al., "Identification and management of overweight and obesity by internal medicine residents," Journal of General Internal Medicine, vol. 20, no. 12, pp. 1139-1141, 2005.

[35] J. Ma, L. Xiao, and R. S. Stafford, "Adult obesity and officebased quality of care in the united states," Obesity, vol. 17, no. 5, pp. 1077-1085, 2009.

[36] S. N. Bleich, O. Pickett-Blakely, and L. A. Cooper, "Physician practice patterns of obesity diagnosis and weight-related counseling," Patient Education and Counseling. 2010. In press.

[37] M. Ezzati, H. Martin, S. Skjold, S. Vander Hoorn, and C. J. L. Murray, "Trends in national and state-level obesity in the USA after correction for self-report bias: analysis of health surveys," Journal of the Royal Society of Medicine, vol. 99, no. 5, pp. 250257, 2006.

[38] E. A. Finkelstein, J. G. Trogdon, J. W. Cohen, and W. Dietz, "Annual medical spending attributable to obesity: payer-and service-specific estimates," Health Affairs, vol. 28, no. 5, pp. w822-w831, 2009.

[39] E. A. Finkelstein, C. J. Ruhm, and K. M. Kosa, "Economic causes and consequences of obesity," Annual Review of Public Health, vol. 26, pp. 239-257, 2005.

[40] G. Blackburn, "Effect of degree of weight loss on health benefits," Obesity Research, vol. 3, supplement 2, pp. 211s216s, 1995.

[41] D. F. Williamson, "Intentional weight loss: patterns in the general population and its association with morbidity and mortality," International Journal of Obesity, vol. 21, supplement 1, pp. S14-S19, 1997. 


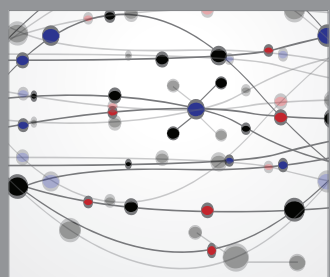

The Scientific World Journal
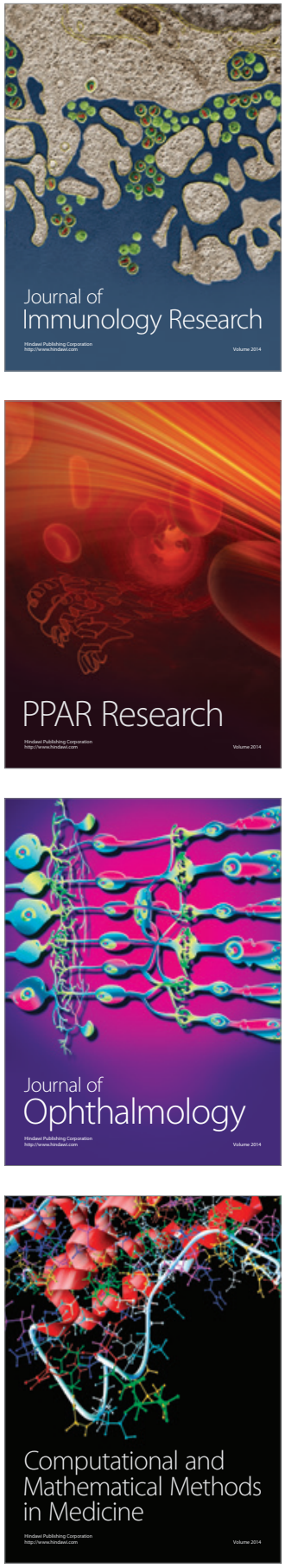

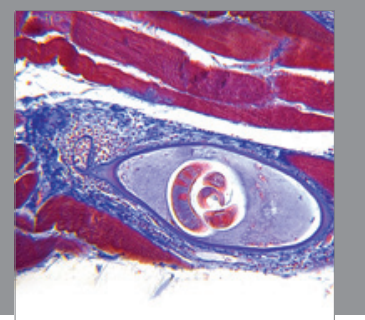

Gastroenterology

Research and Practice
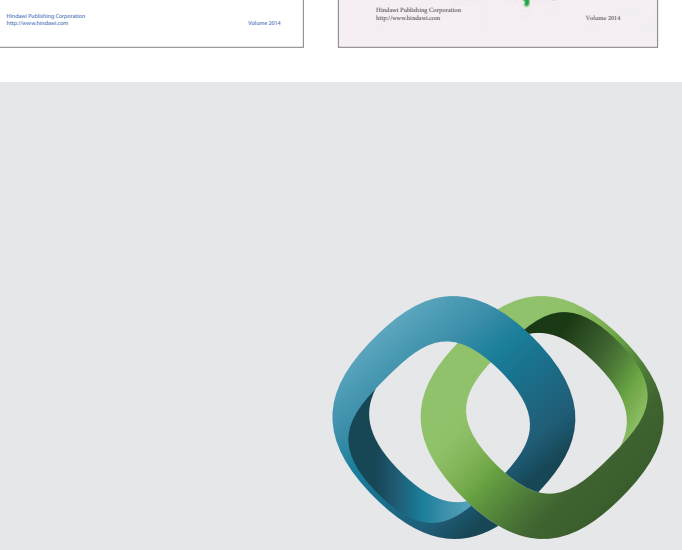

\section{Hindawi}

Submit your manuscripts at

http://www.hindawi.com
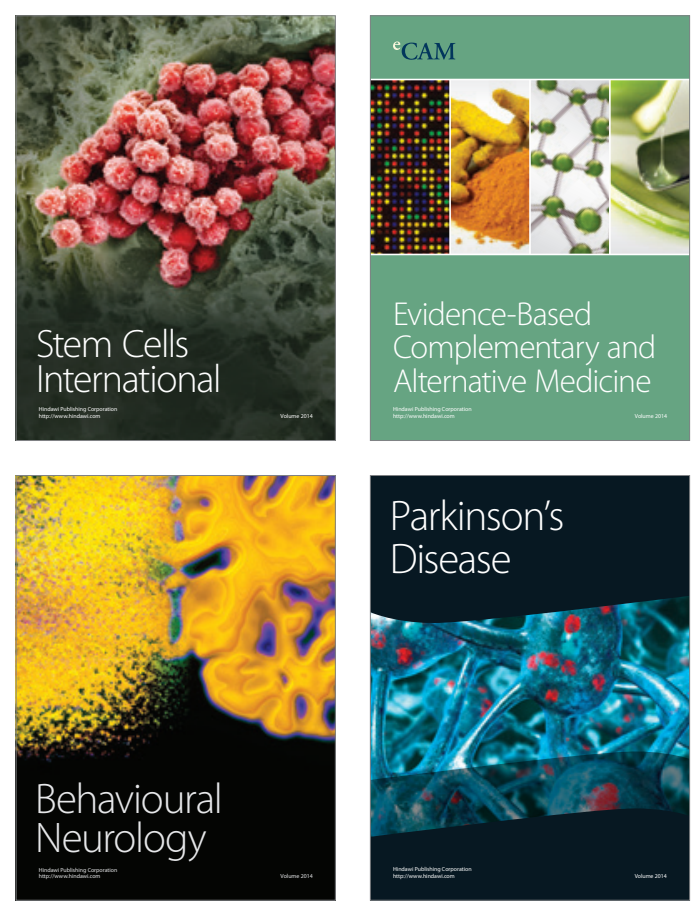

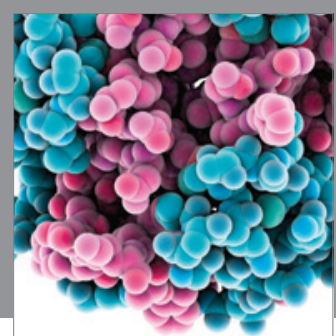

Journal of
Diabetes Research

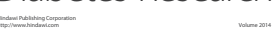

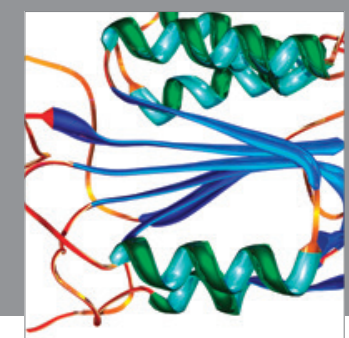

Disease Markers
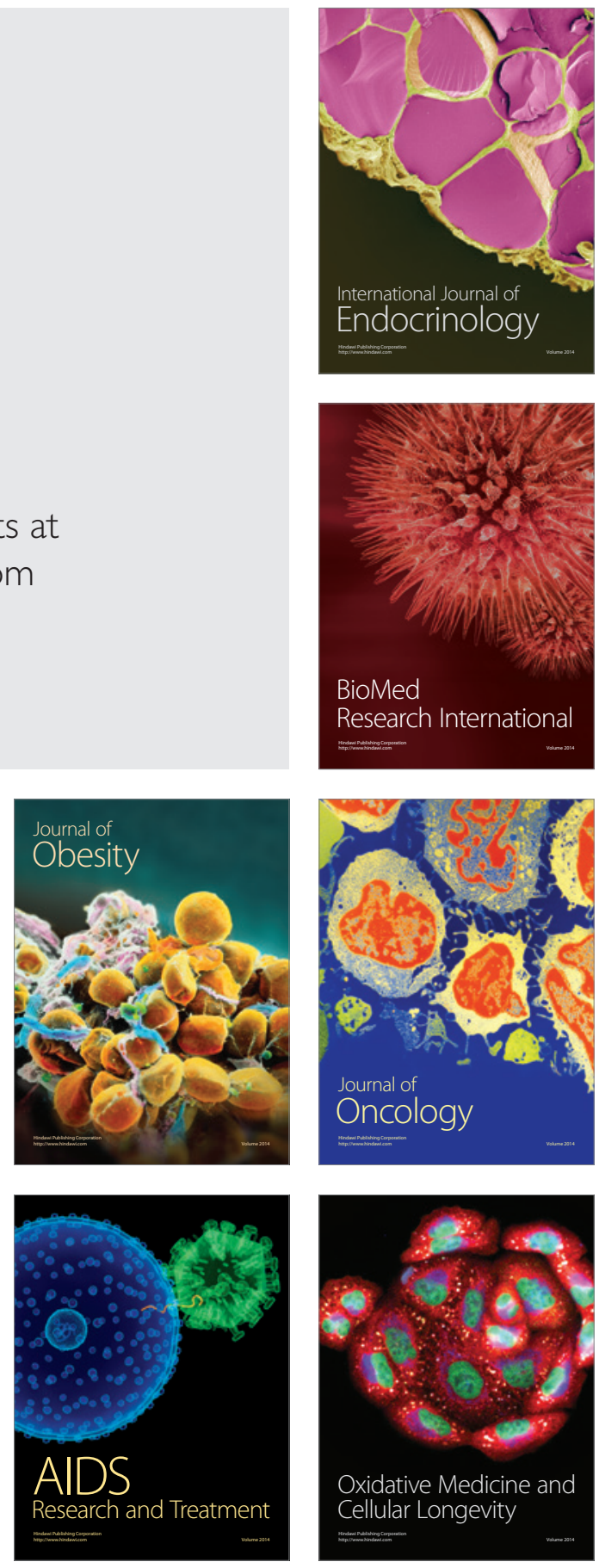